\title{
Utility of FDGPET/CT in the Management of Primary Testicular Lymphoma
}

\author{
Primer Testis Lenfomasında FDG PET/BT'nin Yararılı̆̆ının Değerlendirilmesi
}

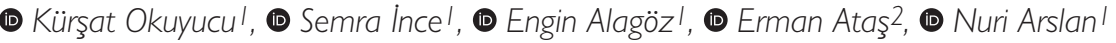 \\ IUniversity of Health Sciences, Gülhane Training and Research Hospital, Clinic of Nuclear Medicine, Ankara, Turkey \\ 2University of Health Sciences, Gülhane Training and Research Hospital, Clinic of Pediatric Oncology, Ankara, Turkey
}

\begin{abstract}
Objective: Primary testicular lymphoma (PTL) is a form of extra-nodal lymphoma originating from the testicles. Currently, positron emission tomography (PET) with glucose analogue 18F-fluorodeoxyglucose (18F-FDG) is the most popular and widely used modality for evaluating tumor metabolism, and PTL usually displays increased 18F-FDG uptake. Despite the rapid increase in clinical applications of FDG PET/ computed tomography (CT), its role in PTL has neither been clearly defined nor reviewed systematically. This study reviews the usefulness and limitation of FDG PET/CT in the diagnosis and treatment of PTL. Methods: This study included 12 patients with PTL between 2004 and 2015. We retrospectively examined PET/CT results along with patient outcome. The maximum standardized uptake value (SUV $\max$ ) was calculated.

Results: The mean overall survival (OS) and disease-free survival (DFS) was 44.5 months and 35.5 months, respectively. The mean SUV $\max$ was identified as 18.5 in recurrent/metastatic group. The 1-year and 3-year OS was $94 \%$ and $69 \%$, while the 1-year and 2-year DFS was $93.5 \%$ and $56 \%$, respectively.

Conclusion: FDG PET/CT is very helpful in both staging and evaluating treatment response. Although it is not a perfect tool in the initial diagnosis, it might aid in the differential diagnosis of challenging testicular tumors. Pre-treatment and posttreatment FDG uptake values may also have a prognostic value in patients with PTL.

Keywords: Primary testicular lymphoma, SUV max $_{1}$ FDG PET/CT
\end{abstract}

\section{Öz}

Amaç: Primer testis lenfoması (PTL) testis kaynaklı bir ekstranodal lenfomadır. 18F-florodeoksiglukoz (18F-FDG) pozitron emisyon tomografisi/bilgisayarlı tomografi (PET/BT) tümör metabolizmasını değerlendirmede yaygın olarak kullanılmaktadır ve PTL yüksek FDG tutulumu gösterir. FDG PET/BT'nin klinik uygulamalarının gün geçtikçe artmasına rağmen, PTL'deki rolü tam olarak tanımlanmamış ve sistematize edilmemiştir. Bu çalışma FDG PET/BT'nin PTL tanı ve tedavisindeki yararlıık ve kısıtlamalarını araştırmaktadır.

Yöntem: Çalışma 2004-2015 yılları arasında 12 PTL hastasını içermektedir. Olguların geriye dönük olarak FDG PET/BT sonuçları ve gidişatları incelenmiştir. Maksimum standart tutulum değeri $\left(S U V_{\text {maks }}\right)$ hesaplandı.

Bulgular: Ortalama toplam sağkalım (OS) ve hastalıksız sağkalım (DFS) sırasıyla 44,5 ay ve 35,5 ay idi. Ortalama SUV maks rekürrent/metastatik grupta 18,5 idi. OS 1. yılda \%94, 3. yılda \%69; DFS 1. yılda \%93,5, 2. yllda \%56 idi.

Sonuç: FDG PET/BT evreleme ve tedaviye yanıt takibinde çok faydalıdır. Testis tümörlerinin ayıııı tanısının zor olduğu olgularda yararlı olabilir. Fakat ilk tanıda iyi bir yöntem değildir. Tedavi öncesi veya sonrası FDG tutulum değerleri prognostik bir önem taşıyabilir.

Anahtar kelimeler: Primer testis lenfoması, SUV maks, FDG PET/BT

Address for Correspondence: Kürşat Okuyucu MD, University of Health Sciences, Gülhane Training and Research Hospital, Clinic of Nuclear Medicine, Ankara, Turkey Phone: +90 3123044808 E-mail: k.okuyucu@yahoo.com ORCID ID: orcid.org/0000-0002-4481-9531

Received: 20.07.2017 Accepted: 13.12.2017

${ }^{\circ}$ Copyright 2018 by Turkish Society of Nuclear Medicine

Molecular Imaging and Radionuclide Therapy published by Galenos Yayınevi. 


\section{Introduction}

Primary testicular lymphoma (PTL) is a form of extra-nodal lymphoma originating from the testicles (1). PTL constitutes approximately $1-2 \%$ of all non-Hodgkin lymphomas (NHL) and accounts for 1-9\% of all testicular tumors (2). Most patients are older than 60 years of age, with PTL being the most frequent testicular neoplasm in this age group (3). Approximately $80-98 \%$ of PTLs are diffuse large B-cell lymphomas (DLBCL) $(4,5)$. The typical initial symptom is a firm, painless testicular mass with an average tumor size of $6 \mathrm{~cm}$ (5). Synchronous bilateral involvement occurs in 6-10\% while systemic disease is present in $20-30 \%$ of the patients (6). The median overall survival (OS) of PTL is reported to be 4-5 years (7). The most common metastatic sites are contralateral testicle, central nervous system (CNS), skin, adrenal glands, bone marrow, lung and pleura (8).

Diagnostic imaging modalities include ultrasound and magnetic resonance imaging (MRI), which allow simultaneous evaluation of both testicles, paratesticular space and spermatic cord (9). When PTL is suspected, inguinal orchiectomy is required for achievement of successful treatment and establishment of correct histopathologic diagnosis with adequate pathologic specimen. An experienced pathologist is required for difficult cases, since distinguishing some cases from seminoma can be challenging (10). In meta-analysis studies, $60-79 \%$ of the patients have stage $\mathrm{I} / \mathrm{II}$ disease at initial presentation (11). Recommended staging is the same as in other forms of aggressive NHL by positron emission tomography/ computed tomography (FDG PET/CT) and bone marrow biopsy, with the addition of specific CNS staging with lumbar puncture for cerebrospinal fluid analysis and cranial MRI (12). The most frequent metastatic location is CNS with a reported incidence of approximately $45 \%$ (13). $64 \%$ of CNS relapses involve the brain parenchyma (11).

Currently, PET with glucose analogue 18F-fluorodeoxyglucose (18F-FDG) is the most popular and widely used modality for evaluating tumor metabolism, and PTL usually displays increased 18F-FDG uptake (14). Despite the rapid increase in clinical applications of FDG PET/CT, its role in PTL has neither been clearly defined nor reviewed systematically. This study reviews the usefulness and limitation of FDG PET/CT in the diagnosis and treatment of PTL.

\section{Materials and Methods}

This is a retrospective cohort study conducted with $12 \mathrm{PTL}$ patients of DLBC variant treated by surgery (orchiectomy) and R-CHOP (rituximab, cyclophosphamide, doxorubicin, vincristine, prednisolone) between 2004 and 2015 at our institution. Patients with histopathologically confirmed PTL, who have been treated with R-CHOP protocol and had a follow-up of at least two years, with an initial staging or follow-up FDG PET/CT were included. Patients with systemic involvement at initial presentation and who received alternative therapy regimens other than $\mathrm{R}-\mathrm{CHOP}$ as first line therapy protocol were excluded from the study. FDG PET/CT was obtained for primary staging in 8 cases and for evaluation of treatment response in 4 cases. Baseline staging, re-staging or follow-up PET results and patient outcome were retrospectively extracted from patient files. The patients having pathologically increased FDG uptake on baseline or follow-up FDG PET/ CT constituted recurrent/metastatic group. The semiquantitative parameter of maximum standardized uptake value $\left(S U V_{\text {max }}\right.$ ) was calculated on FDG PET/CT. OS was accepted as the time from initial diagnosis to death of any cause or last follow-up. Disease-free survival (DFS) was defined as the period from diagnosis to detection of first relapse or last follow-up.

\section{Ethics Committee Approval and Informed Consent}

The study was approved by Gülhane Training and Research Hospital Institutional Ethics Committee (protocol number: 14044, date: 2014). Informed consent was obtained from all participants.

\section{FDG PET/CT Imaging Protocol}

Patients fasted for at least 6 hours and their blood glucose level were below $150 \mathrm{mg} / \mathrm{dL}$ before the injection of an activity of 370-555 MBq of 18F-FDG calculated according to the patient's bodyweight. Images were acquired one hour later with an integrated PET/CT scanner (Discovery 690-GE Healthcare). Unenhanced low dose CT and PET emission data were performed from mid-thigh to the vertex of the skull in the supine position with the arms raised above the head. CT data was obtained by an automated dose modulation of $120 \mathrm{kVp}$ (maximal 100 $\mathrm{mA}$ ), a collimation of $64 \times 0.625 \mathrm{~mm}$, a measured field of view (FOV) of $50 \mathrm{~cm}$, and a noise index of $20 \%$. These data were reconstructed to images of $0.625 \mathrm{~mm}$ transverse pixel size and $3.75 \mathrm{~mm}$ slice-thickness. PET data was in 3D mode with a scan duration of 2 min per bed position and an axial FOV of $153 \mathrm{~mm}$. A standard technique (random, scatter and attenuation) and an iterative reconstruction (matrix size $256 \times 256$, Fourier rebinning, VUE Point FX [3D] with 3 iterations, 18 subsets) corrected the emission data.

\section{Visual and Quantitative Assessment of FDG PET/CT}

A standard protocol on a dedicated workstation (Volumetrix for PET/CT and AW volume share 4.5, GE Healthcare, Waukesha, WI, USA) calculated the semiquantitative PET/ $\mathrm{CT}$ parameters used in the study. The SUV $\mathrm{Vax}_{\text {max }}$ corrected for body weight was computed with standard methods from the activity of the highest density voxel in three-dimensional tumor region of transaxial whole body images on attenuation-corrected PET/CT images. The corresponding CT scan of lesions were demarcated as a frame if the boundaries of an uptake were difficult to define for the calculation of SUV max. 


\section{Statistical Analysis}

The data were analyzed by IBM Corp. Released 2013 (IBM SPSS Statistics for Windows, Version 22.0. Armonk, NY: IBM Corp.) number and percentage values were used for the description of categorical data; mean, median, standard deviation (SD), minimum ( $\mathrm{min}$ ) and maximum (max) values were used for the description of continuous data. ROC curve was drawn to evaluate the diagnostic accuracy of SUV $\max$ and a cut-off level was determined. Sensitivity and specificity rates were calculated according to the chosen cut-off value. Kaplan-Meier test was used for survival analysis.

\section{Results}

The mean patient age was $57 \pm 15$ years $(21-77)$ and the mean SUV $V_{\text {max }}$ value was $18.5 \pm 7$ (9.8-30.8). Mean OS and DFS were identified as 44.5 months (12-101) and 35.5 months (9-101), respectively. Mean SUV $\max$ was 15.9 in the recurrent/metastatic group. Complete remission was achieved in $5 / 12$ of the cases (42\%). On the other hand, $7 / 12$ (58\%) developed recurrence and/or metastasis during follow-up 5 (42\%) of which died. Median time to progression was 18.6 months. OS at the 1 st year was $94 \%$, $87.5 \%$ at the $2^{\text {nd }}, 69 \%$ at the 3 rd, and $62.5 \%$ at the $5^{\text {th }}$ years. DFS at the first year was $93.5 \%, 56 \%$ at the second year, and $44 \%$ at the $3^{\text {rd }}$ year.

There was a statistically significant difference between recurrent/metastatic group and non-metastatic (complete remission) group according to $S_{U} V_{\max }$ values $(p<0.001)$. ROC curve was drawn to evaluate the diagnostic value of $S U V_{\max }$ (Figure 1). Cut-off value of SUV $V_{\text {max }}$, its associated sensitivity and specificity rates are demonstrated in Table 1.

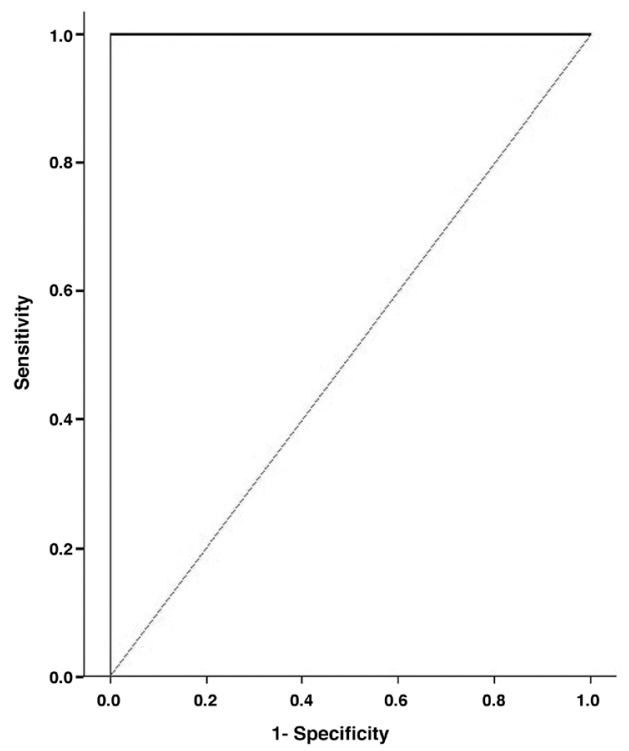

Figure 1. ROC curve represents the diagnostic accuracy of SUV ${ }_{\max }$
Kaplan-Meier method was used to compare DFS and OS of recurrent/metastatic and non-metastatic groups, and curves were plotted for OS (Figure 2) and DFS (Figure 3).

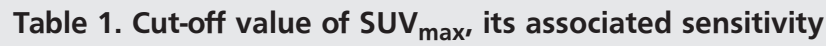
and specificity are demonstrated

\begin{tabular}{llll}
\hline Cut-off value & $\begin{array}{l}\text { Sensitivity } \\
(\%)\end{array}$ & $\begin{array}{l}\text { Specificity } \\
(\%)\end{array}$ & $\begin{array}{l}\text { Area under } \\
\text { curve }\end{array}$ \\
\hline 11.4 & 89 & 100 & $0.99(p=0.001)$ \\
\hline SUV $_{\text {max }}$ : Maximum standardized uptake value
\end{tabular}

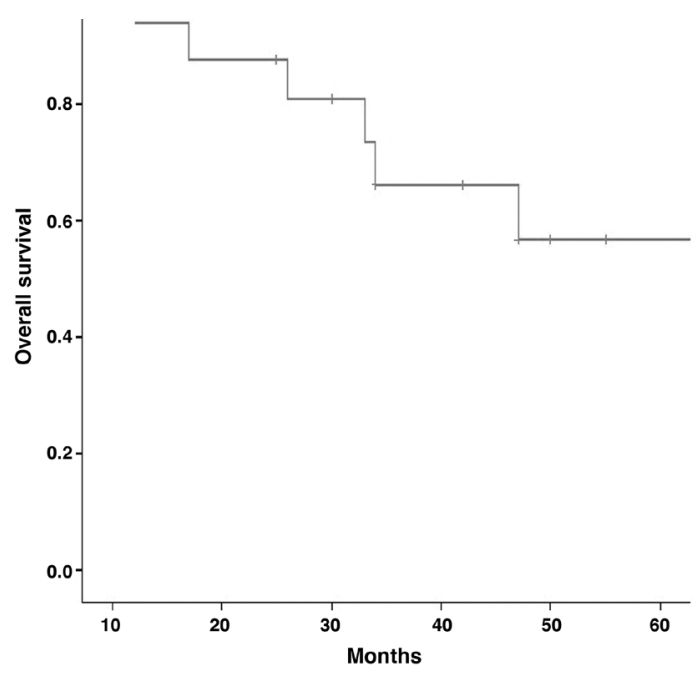

Figure 2. Kaplan-Meier curve shows the plot associated with overall survival

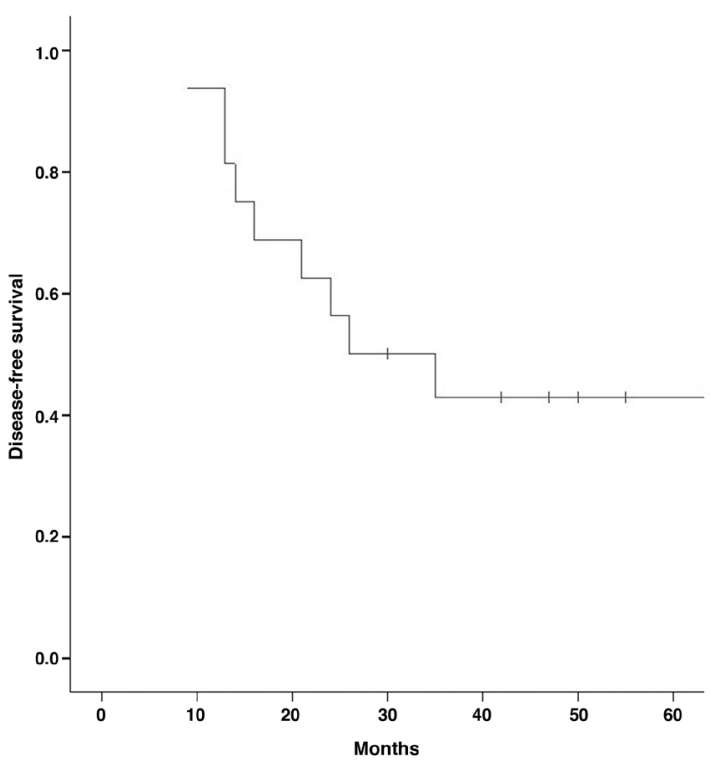

Figure 3. A Kaplan-Meier curve indicates disease-free survival in patients with primary testicular lymphoma 


\section{Discussion}

The mean age of our patient population was 57 years, which is lower than the mean age reported in the literature. The mean tumor size was $6.5 \mathrm{~cm}$ and the mean SUV $\max$ was 18,5, which were both in line with previous studies. Local recurrence was detected in $60 \%$ of the cases and bilateral involvement was present in $16 \%$. Nearly $50 \%$ of the tumors metastasized to CNS, and CNS metastasis and/ or testicular recurrence was the cause of death in all our cases. All these findings including median OS, median time to progression and other prognostic data presented herein are in accordance with the literature.

Early diagnosis of PTL is essential for timely treatment before the occurrence of widespread metastases and invasion of neighboring tissues. Clinical diagnosis of PTL is sometimes difficult and delayed due to its nonspecific symptoms. FDG PET/CT has a limited value in the initial diagnosis and differentiation of PTL from other malignant testicular tumors or non-malignant lesions. PTL is a highly cellular tumor and shows increased glucose metabolism, causing homogenous marked asymmetric testicular FDG uptake (14). The semi-quantitative FDG uptake values measured by SUV $\max$ were reported to be between 10 and 30 for PTL (14). This value is higher than the average SUV max of the normal testicle that has been reported as approximately 2.5 in large case series (14). PTL may be distinguished from other testicular diseases such as seminoma according to its uptake pattern and SUV max value. However, FDG PET/CT is not a perfect tool in the diagnosis of PTL.

Detection of PTL with extra-testicular involvement at primary (baseline) staging is important for appropriate therapy since systemic involvement alternates therapy protocol. Standard baseline (initial) staging for PTL includes MRI and sometimes bone marrow biopsy to exclude systemic lymphoma (13). Conventional initial staging in PTL might not show extra-testicular lesions, especially occult systemic lymphoma in some patients. FDG PET/CT is more sensitive than conventional staging methods in this regard and may disclose higher rates of concomitant systemic disease at initial diagnosis. The supremacy of this modality is attributed to the ability to screen the whole-body, and the fusion of anatomic detail provided by the CT component with metabolic information. This advantage remains true also for re-staging during follow-up. The clinical significance of identifying recurrence and/or metastasis at the follow-up is apparent. Currently, FDG PET/CT is the choice of imaging modality for primary staging and re-staging. In our study, we also observed that FDG PET/CT is an excellent tool in disease-staging both initially and during follow-up.

PTL is one of the most malignant testicular tumors that respond well to treatment. Changes in metabolic imaging with FDG PET/CT can be detected soon after initiation of therapy. Early evaluation of the initial treatment response is very important, since salvage treatment may improve outcome. Follow-up (evaluation of treatment response) FDG PET/CT fulfills this easily with its unique advantages over conventional techniques. The whole body can be assessed in one session prior to anatomic changes and active foci can be distinguished from fibrotic or inflammatory tissue as well as detection of small lesions located outside areas imaged by conventional techniques. Dramatic disappearance of increased FDG uptake in the tumor with therapy indicates treatment success.

Kawai et al. (15) demonstrated that FDG PET 3 weeks after the first chemotherapy showed a significant decrease in FDG uptake of the tumor as compared to pre-treatment uptake. The reduction in FDG uptake significantly correlated with the decrease in tumor size as detected by follow-up MRI (15). These results indicate that metabolic imaging with FDG PET can accurately evaluate treatment response at an early stage, sometimes preceding changes on MRI. Early therapeutic monitoring might have an impact on deciding whether the treatment regimen should be maintained or changed. If patients with a poor early response were identified, treatment could be modified at an early stage before delivering additional cycles of ineffective therapy. In our study, we detected that follow-up FDG PET provided valuable information for treatment evaluation.

The 5-year survival rate is reported as 35\% with a mean survival of 13 months for patients with PTL (16). The 5-year survival rate was identified as $53 \%$ in our study, with a mean survival of 18 months. Early quantitative measurement of metabolic response with FDG PET was declared to provide valuable prognostic information in systemic aggressive lymphoma types (15). FDG PET/CT might also provide prognostic information in patients still under therapy and predict long-term outcome in PTL. The OS of patients with low to moderate FDG uptake was reported to be significantly longer than that of patients with high FDG uptake (17). PTL with high FDG uptake tended to exhibit poor treatment response as compared to that with low to moderate uptake (18). This prognostic information yielded

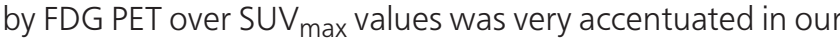
study. The SUV max of the recurrent/metastatic group was significantly high $(p<0.001)$ and it was a strong predictor of outcome. To the best of our knowledge, although there are no published studies on this issue in the literature, FDG uptake value might represent tumor aggressiveness in PTL. Further clinical trials are required to define the optimal strategy to utilize FDG PET information as a prognosticator and to improve outcome in patients with PTL.

\section{Conclusion}

The utility of FDG PET/CT is currently increasing in the management of PTL. This review summarizes the usefulness and limitations of FDG PET/CT in the diagnosis and treatment of PTL. FDG PET/CT is valuable in both primary staging and restaging. It is also valuable in evaluating 
treatment response after initial chemotherapy and altering treatment strategy at a very early stage, if required. Preand post-treatment FDG uptake values reflected by $S U V_{\max }$ might have a prognostic value in patients with PTL. FDG PET/CT might be useful for differential diagnosis of challenging testicular tumors. Nevertheless, it is not the proper modality for initial diagnosis.

\section{Ethics}

Ethics Committee Approval: The study was approved by Gülhane Training and Research Hospital Institutional Ethics Committee (protocol number: 14044, date: 2014).

Informed Consent: Informed consent was obtained from all participants.

Peer-review: Externally peer-reviewed.

\section{Authorship Contributions}

Surgical and Medical Practices: K.O., S.I., E.A., E.A., N.A., Concept: K.O., S.I., E.A., E.A., N.A., Design: K.O., S.I., E.A., E.A., N.A., Data Collection or Processing: K.O., S.I., E.A., E.A., N.A., Analysis or Interpretation: K.O., S.i., E.A., E.A., N.A., Literature Search: K.O., S.i., E.A., E.A., N.A., Writing: K.O., S.I., E.A., E.A., N.A.

Conflict of Interest: No conflict of interest was declared by the authors.

Financial Disclosure: The authors declared that this study has received no financial support.

\section{References}

1. Cakiroglu B, Eyyupoglu SE, Dogan AN, Noseri U, Aksoy SH, Ozturk AB. Primary testicular lymphoma: Two case reports and review of the literature. Arch Ital Urol Androl 2016;87:332-334.

2. Shahab N, Doll DC. Testicular lymphoma. Semin Oncol 1999;26:259269.

3. Kim J, Yoon DH, Park I, Kim S, Park JS, Lee SW, Huh J, Park CS, Suh C. Treatment of primary testicular diffuse large B cell lymphoma without prophylactic intrathecal chemotherapy: a single center experience. Blood Res 2014;49:170-176.

4. Park BB, Kim JG, Sohn SK, Kang HJ, Lee SS, Eom HS, Kwon HC, Oh SY, Kang JH, Oh SJ, Shin HJ, Suh C, Kim JH, Kim HY, Kim K, Ryoo BY, Kim WS. Consideration of aggressive therapeutic strategies for primary testicular lymphoma. Am J Hematol 2007;82:840-845.

5. Cheah CY, Wirth A, Seymour JF. Primary testicular lymphoma. Blood 2014;123:486-493
6. Horne MJ, Adeniran AJ. Primary diffuse large B-cell lymphoma of the testis. Arch Pathol Lab Med 2011;135:1363-1367.

7. Jia B, Shi Y, Dong M, Feng F, Yang S, Lin H, Zhou L, Zhou S, Chen S, Yang J, Liu P, Qin Y, Zhang C, Gui L, Wang L, Wang X, He X. Clinical features, survival and prognostic factors of primary testicular diffuse large B-cellymphoma. Chin J Cancer Res 2014;26:459-465.

8. Lokesh KN, Sathyanarayanan V, Kuntegowdanahalli CL, Suresh TM, Dasappa L, Kanakasetty GB. Primary Diffuse large B-Cell lymphoma of testis: A single centre experience and review of literature. Urol Ann 2014;6:231-234.

9. Srisuwan T, Muttarak M, Kitirattrakarn P, Ya-in C. Clinics in diagnostic imaging (134). Testicular lymphoma. Singapore Med J 2011;52:204208.

10. Ponti G, Ponzoni M, Ferreri AJ, Foppoli M, Mazzucchelli L, Zucca E. The impact of histopathologic diagnosis on the proper management of testis neoplasms. Nat Clin Pract Oncol 2008;5:619-622.

11. Zucca E, Conconi A, Mughal TI, Sarris AH, Seymour JF, Vitolo U, Klasa R, Ozsahin M, Mead GM, Gianni MA, Cortelazzo S, Ferreri AJ, Ambrosetti A, Martelli M, Thiéblemont C, Moreno HG, Pinotti G, Martinelli G, Mozzana R, Grisanti S, Provencio M, Balzarotti M, Laveder F, Oltean G, Callea V, Roy P, Cavalli F, Gospodarowicz MK; International Extranodal Lymphoma Study Group. Patterns of outcome and prognostic factors in primary large-cell lymphoma of the testis in a survey by the International Extranodal Lymphoma Study Group. J Clin Oncol 2003;21:20-27.

12. Benevolo $G$, Stacchini $A$, Spina $M$, Ferreri $A J$, Arras $M$, Bellio $L$, Botto B, Bulian P, Cantonetti M, Depaoli L, Di Renzo N, Di Rocco A, Evangelista A, Franceschetti S, Godio L, Mannelli F, Pavone V, Pioltelli P, Vitolo U, Pogliani EM; Fondazione Italiana Linfomi. Final results of a multicenter trial addressing role of CSF flow cytometric analysis in NHL patients at high risk for CNS dissemination. Blood 2012;120:3222-3228.

13. Lote $\mathrm{K}$, Holte $\mathrm{H}$, Kvaloy $\mathrm{S}$. Testicular lymphoma is associated with a high risk of extranodal recurrence. Cancer 2000;89:713-714.

14. Kitajima K, Nakamoto Y, Senda M, Onishi Y, Okizuka H, Sugimura K. Normal uptake of F18-FDG in the testis: an assessment by PET/CT. Ann Nucl Med 2007;21:405-410.

15. Kawai N, Zhen HN, Miyake $K$, Yamamaoto $Y$, Nishiyama $Y$, Tamiya T. Prognostic value of pretreatment 18F-FDG PET in patients with primary central nervous system lymphoma: SUV-based assessment. J Neurooncol 2010;100:225-232.

16. Scotti SD, Laudadio J. Testicular relapse of non-Hodgkin Lymphoma noted on FDG-PET. J Radiol Case Rep 2009;3:18-24.

17. Lin C, Itti E, Haioun C, Petegnief Y, Luciani A, Dupuis J, Paone G, Talbot JN, Rahmouni A, Meignan M. Early 18F-FDG PET for prediction of prognosis in patients with diffuse large B-cell lymphoma: SUV-based assessment versus visual analysis. J Nucl Med 2007;48:1626-1632.

18. Vamsy M, Dattatreya P, Parakh M, Dayal M, Rao VP. F18 FDG positron emission tomography revelation of primary testicular lymphoma with concurrent multiple extra nodal involvement. Indian J Nucl Med 2013;28:36-38. 